\section{LA FÁBRICA DE LA EMPATÍA. DEL DETERMINISMO GENÉTICO AL ORIGEN SOCIAL DE LA MORAL}

\author{
David Hernández Castro \\ Universidad Nacional de Educación a Distancia \\ davidhernandezcastro@gmail.com
}

Cómo citar este artículo/Citation: Hernández Castro, D. (2016). La fábrica de la empatía. Del determinismo genético al origen social de la moral. Arbor, 192 (779): a321. doi: http://dx.doi. org/10.3989/arbor.2016.779n3011

Recibido: 6 septiembre 2014. Aceptado: 26 diciembre 2015.

RESUMEN: Preston y De Waal han adoptado una idea teórica, el Mecanismo de Percepción-Acción (MPA), que sugiere que la empatía y la moral tienen raíces genéticas y evolutivas. En este artículo analizamos críticamente el MPA y proponemos una interpretación alternativa, la fábrica de la empatía, que reconsidera la "Hipótesis de la Percepción-Acción" y el descubrimiento de las neuronas espejo bajo la luz del concepto de performatividad de Judith Butler y la construcción social de las emociones. Frente al determinismo genético, nuestra investigación apunta a las relaciones sociales y el lenguaje.

PALABRAS CLAVE: Determinismo genético; Preston y De Waal; Mecanismo de Percepción-Acción (MPA); psicología evolucionista; empatía; moral.

\section{THE EMPATHY FACTORY. FROM GENETIC DETERMINISM TO SOCIAL ORIGIN OF MORALITY}

Copyright: (C) 2016 CSIC. Este es un artículo de acceso abierto distribuido bajo los términos de la licencia Creative Commons Attribution (CC BY) España 3.0.

ABSTRACT: Preston and De Waal have adopted a theoretical idea known as the "Perception-Action Model" (PAM), which suggests that empathy and morality have genetic and evolutionary roots. In this paper, the author proposes a critical reading of PAM and an alternative interpretation, "the empathy factory", which reconsiders the "Perception-Action Hypothesis" and the discovery of mirror neurons in the light of Judith Butler's concept of performativity and the social construction of emotions. The conclusion is that the origin of the moral impulse does not lie in genetic determinism but in social relationships, language and affective communication.

KEYWORDS: Genetic determinism; Preston \& De Waal; Perception-Action Model (PAM); Evolutionary Psychology; empathy; morality. 
"Incluso hoy en día, si un grupo de hombres ve a un niño a punto de caerse en un pozo, sentirán -sin excepciónun profundo sentimiento de angustia y alarma".

Mencio

Libro de Mencio, II, 1, 6 (De Waal, 2007a, p. 79)

"Después de un rato, llegaron unos camiones de basura cargados con niños. Había como unos diez. Cuando entraron en el patio, uno de los oficiales dio una orden, los camiones comenzaron a recular hacia la hoguera y empezaron a arrojar a los niños al fuego. Los niños empezaron a gritar y algunos consiguieron escapar del hoyo del fuego; un oficial se acercaba con un bastón y volvía a echar al fuego a quienes habían logrado escapar. Hoess y Mengele estaban presentes dando órdenes".

Relato de un superviviente de Auschwitz (Posner y Ware, 2005, p. 101)

\section{INTRODUCCIÓN: EL DETERMINISMO GENÉTICO Y EL ORIGEN DE LA MORAL}

A lo largo de su historia, la especie humana se ha mostrado convencida de encontrarse abocada a un destino mucho más elevado del que cabría suponerle por su condición animal. Para alcanzar este destino invirtió considerables dosis de esfuerzo y voluntad en la construcción de un edificio imponente: la moral. Pero el siglo XX sacudió sus cimientos de una manera tal que muchos empezaron a preguntarse si en realidad no serían el resto de los animales los que se han elevado por encima de la especie humana. Si algo nos ha enseñado Auschwitz es que la clase de refinamiento en la maldad que estuvo al alcance de Hoess y Mengele transciende cualquier expresión de brutalidad que podamos encontrar en el resto de la naturaleza. Para iniciarse en ella es necesario tener intenciones. Y muy pocos animales han demostrado ser dueños de algo parecido. Los simios, según De Waal, estarían entre ellos. Pero ni siquiera los simios han sido capaces de desarrollar el tipo de intencionalidad que supone la planificación de algo tan vasto como Auschwitz. Esta capacidad pertenece en exclusiva al inventor de la moral, el animal humano.

La perplejidad a la que conduce la conclusión anterior es la que se encuentra en el centro del debate en torno a los orígenes naturales de la moral. En los años sesenta, Robert Ardrey popularizó la idea de que el ser humano proviene de una especie de "simios asesinos" (Ardrey, 1961 y 1966). Con la historia de la Segunda Guerra Mundial todavía reciente, la teoría parecía fácil de aceptar. Pero pronto empezaron a surgir voces críticas que cuestionaron el rigor científico de sus investi- gaciones (Asheley Montagu y otros, 1970). Se trata de una cuestión vieja para la filosofía: Homo homini lupus ("El hombre es un lobo para el hombre"), el antiguo proverbio romano que Thomas Hobbes reintrodujo en el debate político y que Frans de Waal colocó en el frontispicio de lo que ha descrito como la "teoría de la capa" (2007a, pp. 23-87). Según esta interpretación, los seres humanos no somos verdaderamente morales, sino que la moralidad es "un revestimiento cultural, una fina capa que oculta una naturaleza egoísta y brutal" (De Waal, 2007a, p. 30). El fondo de la cuestión es el siguiente: ¿cuál es la naturaleza del ser humano? ¿Es un animal esencialmente moral, o es la moralidad una pátina cultural que nos protege de nuestros instintos más primarios? A esta pregunta, De Waal responde cuestionando las premisas. No es cierto que el acervo genético del que somos portadores sea únicamente testimonio de una historia evolutiva de lucha por la existencia, si entendemos esta lucha en los términos del darwinismo social, con el equipaje completo de pasiones egoístas, brutalidad y competencia descarnada. Estos impulsos forman parte de nuestra herencia evolutiva, pero se han desarrollado al mismo tiempo que otras tendencias genuinamente cooperativas y altruistas, cuyo papel ha sido determinante para la emergencia de la moral. "Tenemos la fortuna de poseer -dice De Waal- no uno, sino dos simios ${ }^{1}$ interiores" (De Waal, 2007b, p. 249). Y más adelante añade:

"La visión que nos retrata como egoístas y mezquinos, con una moralidad irrisoria, debe revisarse. Si somos esencialmente antropoides, como yo argumentaría, o al menos descendientes de antropoides, como argüiría cualquier biólogo, entonces nacemos con una gama de tendencias, desde las más básicas hasta las más nobles. Lejos de ser un producto de la imaginación, nuestra moralidad es el resultado del mismo proceso de selección que conformó nuestro lado competitivo y agresivo" (De Waal, 2007b, p. 250).

De Waal es sin duda uno de los investigadores mejor cualificados para realizar una afirmación como esta. Lo que hoy conocemos en el ámbito de la primatología es en gran parte deudor de sus importantes proyectos de investigación con bonobos, chimpancés y otros primates. Sus detallados relatos acerca de la presencia entre nuestros parientes más cercanos de actos concretos de cooperación, consuelo y altruismo, han terminado de socavar la teoría del "simio asesino". Y sin embargo, a pesar de todo, hay algo que De Waal comparte con esta teoría. Para poder apreciarlo, es necesario ampliar el encuadre de la escena. Más allá del debate en torno a qué clase de herencia evo- 
lutiva ha cristalizado en la naturaleza humana, si se trata de una herencia de impulsos brutales y egoístas, o sociables y cooperativos, o de una presencia conflictiva de todos ellos, la cuestión a dilucidar es si los impulsos que constituyen la naturaleza humana pueden ser definidos en clave de herencia evolutiva. El empeño de De Waal es demostrar que las "tendencias altruistas y compasivas" que caracterizan a (algunos) seres humanos son un producto de las mismas fuerzas evolutivas que promueven el interés propio (2007a, p. 38). Pero esto no significaría que podamos establecer una relación necesaria entre nuestro comportamiento moral y nuestra determinación genética. Los seres humanos, dice De Waal, no somos "actores ciegos que ejecutan programas genéticos", sino "improvisadores que se adaptan con flexibilidad a otros improvisadores en liza" (2007a, p. 235). Sin embargo, desde la perspectiva del debate sobre las raíces biológicas de la moral, lo que debería interesarnos no es el margen de maniobra que tiene el ser humano respecto a sus instintos, sino la afirmación de que "es innegable que tenemos predisposiciones innatas", y que estas predisposiciones están codificadas genéticamente ofreciendo a la moral un arsenal de "pistas y sugerencias" que contribuyen a orientarla (2007a, p. 235). Para De Waal, en resumen, la moralidad es una "prolongación directa de los instintos sociales que compartimos con otros animales" (2007a, p. 30). Hay aquí un elemento que no deberíamos pasar por alto. De Waal, al señalar que la moral es el resultado de instintos sociales, se ocupa de marcar sus diferencias con respecto a un autor como Dawkins, que se plantea la emergencia de la moral como una ruptura contra la carga evolutiva del ser humano (De Waal, 2007a, pp. 33-34). Esta es la razón por la que Dawkins dedicó todo un capítulo de su obra The extended phenotype a explicar por qué no se considera un determinista genético (1982, pp. 9-29). Al igual que hemos visto sostener a De Waal que los seres humanos no somos "actores ciegos" que ejecutan programaciones genéticas, Dawkins afirma que el ser humano puede rebelarse "contra la tiranía de los replicadores egoístas" (1993, p. 232). Pero hay una diferencia entre considerar que la especie humana puede ser moral a pesar de sus determinaciones biológicas, y la afirmación de que es solo gracias a ellas como puede convertirse en un ser moral. De Waal hace de esta diferencia el motivo de su distanciamiento de la "teoría de la capa", una idea que De Waal remonta a Huxley y que básicamente consistiría en reducir la moralidad a "una fina corteza bajo la cual bullen pasiones antisociales, amorales y egoístas" (De Waal, 2007a, p. 34). Para De Waal, por el contrario, la moralidad no es una rebelión contra una naturaleza egoísta, sino la emergencia dentro de esta misma naturaleza de otro tipo de predisposiciones que también forman parte de ella.

A pesar de los esfuerzos de De Waal y Dawkins por apartarse de las versiones más groseras del determinismo genético, es muy difícil escapar del campo de gravedad de esta teoría cuando se parte de la premisa de que los instintos o la conducta de los seres humanos pueden ser explicados como un resultado de la adaptación evolutiva. Dawkins, dentro de esta perspectiva, es determinista no porque considere que los genes tengan la última palabra de la conducta humana, o que todos los modelos de conducta puedan ser explicados por adaptación natural, sino porque considera que la selección genética tiene algo que decir en nuestra compresión de los modelos de conducta humana, sea solo parcialmente, y aunque desechemos todos "los mitos populares de la capacidad de determinación calvinista de los genes" (Dawkins, 1982, pp. 18-19, 29). Así, el determinismo biológico más estrecho ha sido desplazado por otros enfoques más receptivos con las influencias sobre el comportamiento social de las complejas interacciones entre biología y medio ambiente. La psicología evolucionista ocupa en este nuevo escenario un lugar destacado, a partir de su investigación de la arquitectura que subyace a la mente de los primates, interpretada en clave de mecanismos funcionales o adaptaciones psicológicas desarrolladas mediante selección natural. Steven Pinker, uno de sus defensores más conocidos, cita a Dawkins para explicar que la teoría de la evolución centrada en los genes no implica una motivación consciente y egoísta de las personas, sino que son los genes quienes de forma egoísta "se propagan a sí mismos y lo hacen al construir nuestros cerebros" (Pinker, 2000, p. 67). Y más adelante añade: "Nuestras metas son submetas de la meta última que tienen los genes: replicarse a sí mismos. Pero las dos metas son diferentes" (Pinker, 2000, p. 68). Aunque Frans de Waal se distancia de Pinker y de la psicología evolucionista en ciertos aspectos, como en su rechazo a la posibilidad de una irrupción discontinua del "módulo" del lenguaje (De Waal, 2007a, p. 48), o la tendencia a asignar genes o "módulos cerebrales" para funciones específicas (De Waal, 2002, p. 189), asume la conexión entre la conducta social y la programación genética, y augura que, una vez liberada de ciertas etiquetas y y presuposiciones, la psicología evolucionista terminará consiguiendo que en todos los departamentos de psicología del futuro cuelgue un retrato de Darwin (De Waal, 2002, p. 190). Pero para De Waal esto no 
significa que la teoría de los psicólogos evolucionistas, ni la suya propia, caiga dentro del determinismo genético, porque aunque enfatiza la evolución genética más de lo que los psicólogos han solido hacerlo, no lo hace excluyendo otras interpretaciones (De Waal, 2002, p. 187). Si nos atenemos a las versiones más estrechas del determinismo genético, obviamente debemos darle la razón. Pero De Waal afirma que la moralidad es el resultado de los instintos sociales, y utiliza para fundamentarlo una teoría que al igual que los mecanismos psicológicos evolucionados de la psicología evolucionista, atribuye las raíces de determinados comportamientos a predisposiciones innatas. Se trata del Mecanismo de Percepción-Acción (MPA), un modelo que De Waal presentó junto a Preston en dos artículos publicados el mismo año (Preston y De Waal, 2002a y 2002 b), y en el cual se daba cuenta del fenómeno del contagio emocional y la empatía como el resultado de un proceso de adaptación evolutiva. Por consiguiente, como ha señalado Susan McKinnon, la verdadera diferencia entre la teoría de la mente de la psicología evolucionista y la que subscriben la mayoría de los antropólogos culturales, no es "si la vida mental tiene en parte una base orgánica o si es un desarrollo complejo y una relación interactiva entre los organismos y su entorno", sino más bien, continua McKinnon citando a Benson, si es posible establecer "cuánta arquitectura heredada hay en la mente humana" y "si los procesos socioculturares se entienden como independientes o como reducibles a mecanismos psicológicos heredados", siendo estos, a su vez, interpretables en términos de maximización genética (McKinnon, 2012, p. 20; Benton, 2000).

Dedicaremos el próximo apartado a explicar el funcionamiento del MPA, para pasar a continuación al cuerpo central de este artículo: una crítica a la postura de Preston y De Waal, así como una propuesta alternativa de interpretación de la hipótesis de percepciónacción que hemos llamado la fábrica de la empatía. En nuestra opinión, el MPA no satisface la pretensión de sus autores de fundamentar un núcleo de predisposición innata a la empatía. Por el contrario, los instintos y emociones que se manifiestan en los procesos de contagio emocional, pese a ser espontáneos y aparentemente "naturales", están construidos socialmente.

\section{EL MECANISMO DE PERCEPCIÓN-ACCIÓN DE PRESTON YDE WAAL}

Para De Waal, el comportamiento humano "es una combinación de instinto e inteligencia", y dentro de esta combinación, por lo general, el papel de la inteligencia está por encima de los instintos. "El comportamiento humano -señala- es en gran parte influenciable por la experiencia" (De Waal, 2007b, p. 235). El problema aquí no es tanto el concepto de la combinación de instinto e inteligencia, como el hecho de considerar que estas esferas del comportamiento pueden ser reducidas a un ámbito propio antes de la combinación. De Waal, que se ha mostrado muy atento para prevenir a la psicología evolucionista de la propensión al dualismo de la tradición filosófica occidental, una tradición que separa el cuerpo de la mente, lo humano de lo animal, y la naturaleza de la cultura (De Waal, 2002, p. 187), no ha sido capaz de liberarse de otra manifestación de este dualismo: la que separa a los instintos de la inteligencia, como si la "combinación" que nos encontramos al final del proceso tomara como punto de partida dos compartimentos estancos. Lo hemos señalado anteriormente. Lo verdaderamente relevante para establecer el carácter de la postura de De Waal, no es si amplía el margen de operatividad del ser humano en relación a sus instintos, sino la presunción de que existe algo así como unos "instintos" o "predisposiciones innatas", y por tanto, previos a su determinación social, que pueden ser asociados con inclinaciones morales y explicados a través de la selección natural. Preston y De Waal asumieron esta condición "innata" para las manifestaciones de contagio emocional que constituyen la primera fase de la respuesta empática, después de vincularla con el tipo de afección emocional que los animales gregarios parecen sentir unos por otros (Preston y De Waal, 2002b, pp. 6-7).

Junto a esta consideración, el Mecanismo de Percepción-Acción (MPA) parte de otro supuesto. Somos agentes morales racionales, pero las emociones constituyen un elemento fundamental en la toma de decisiones. "Las emociones triunfan sobre las reglas", dice De Waal. "Por eso -añade-, al hablar de modelos de conducta moral, hablamos de nuestros corazones y no de nuestros cerebros" (De Waal, 2007b, p. 226). Las decisiones que tomamos están más influidas por lo que sentimos que por lo que pensamos. Las emociones actúan como una brújula moral (De Waal, 2007b, p. 194). Nos ofrecen inhibiciones que orientan nuestra conducta. "A menudo las racionalizaciones vienen después, cuando ya hemos llevado a cabo las reacciones prefijadas de nuestra especie" (De Waal, 2007b, p.195). Estas reacciones tienen que ver con determinadas "partes del cerebro que se remontan a la transición de los reptiles de sangre fría a los amables, cariñosos y solícitos mamíferos que somos" (De Waal, 2007b, 
p. 195). Hay, por consiguiente, una conexión entre las actividades psicológicas que forman parte de la moral, y las actividades neurales que constituyen su soporte biológico. Esta conexión es lo que Preston y De Waal Ilamaron Mecanismo de Percepción-Acción (Preston y De Waal, 2002a y 2002b), que ellos ubican en el centro de la capacidad para sentir empatía, y que consiste en un "mecanismo relativamente sencillo que permite al observador (el "sujeto») acceder al estado emocional del prójimo (el «objeto») a través de las representaciones neurales y corporales del propio sujeto" (De Waal, 2007a, p. 64). El "contagio emocional" es el estado que traduce en el sujeto este impacto emocional automático, "una equiparación entre individuos inmediata y a menudo inconsciente de sus respectivos estados" (De Waal, 2007a, p. 66).

En el caso de los humanos, Preston y De Waal (2002a) también definen a este estado de contagio emocional como una "angustia personal" (personal distress), una condición que debemos distinguir de la empatía propiamente dicha. La diferencia con el contagio emocional radica en que la empatía mantiene una distinción subjetiva entre el sí mismo y el otro, de manera que el estado emocional permanece centrado en el objeto en lugar del sujeto. "Esto puede dar lugar o no a la prestación de ayuda o acciones de apoyo para paliar la angustia del objeto". La empatía, añaden Preston y De Waal, "es un fenómeno de estado-compartido, la definición generalmente implica cierto grado de coincidencia de estado" (Preston y De Waal, 2002a, p. 286).

La empatía se representa entonces más como un proceso que como un resultado, y sustituye la imagen de la teoría de la capa por el Modelo de la Muñeca Rusa. En el núcleo de este Modelo se encuentra el MPA, que está programado genéticamente para producir el estado de contagio emocional que acaba de ser descrito. Y en los niveles más elevados se sitúa la empatía cognitiva, que se ocupa, por ejemplo, de entender las razones del prójimo y la atribución del estado mental, y en virtud de la cual se adopta plenamente la perspectiva ajena (De Waal, 2007a, p. 66).

Todo el mecanismo se sustenta sobre un supuesto teórico, que es la idea de que la percepción y la acción comparten un código común de representación en el cerebro. Esta disposición es consecuencia de que el desarrollo de los sistemas de percepción habría estado condicionado por la necesidad de ofrecer información precisa sobre el medio ambiente, en orden a la planificación adecuada y la orientación de los movimientos. Estos códigos comunes no están necesariamente restringidos al ámbito de los movimientos físicos, sino que incluyen también abstracciones y representaciones simbólicas. Por consiguiente, en el caso de las emociones, "las representaciones no solo necesitan reproducir posturas corporales y expresiones faciales directamente del agente al perceptor; sino que pueden reproducir los sentidos o los objetivos de las expresiones" (Preston y De Waal, 2002a, p. 301). Se trata, en definitiva, de que hay un vínculo del sistema nervioso entre la acción y la percepción que nos ayuda a orientarnos por el entorno físico, y que este mismo vínculo es el que nos permite orientarnos por el entorno social. Nos permite adquirir tanto las habilidades motoras básicas como las que regulan las interacciones sociales más simples.

De Waal recurre a una amplia base de literatura científica para respaldar su argumento sobre la conexión entre los procesos de percepción motora y emotiva:

"Los datos sugieren que tanto la observación como la experimentación de las emociones implica una serie de sustratos psicológicos compartidos: ver el desagrado o el dolor del prójimo es muy parecido a sentirlo. La comunicación afectiva también crea estados psicológicos parecidos en el sujeto y el objeto" (De Waal, 2007a, p. 65).

EI MPA queda así constituido como el eslabón que conecta la moralidad con la estructura biológica del ser humano. El primer eslabón de la cadena son las emociones. La moralidad es un dominio que está anclado en las emociones sociales, pero estas emociones tienen su centro en la empatía, y la empatía, en su núcleo estructural, alberga al Mecanismo de Percepción-Acción. El mecanismo produce una "activación" neural, automática e inconsciente, que permite al individuo ponerse en la piel del otro, "compartiendo sus sentimientos y necesidades, lo cual promueve a su vez la simpatía, la compasión y la capacidad de ayuda" (De Waal, 2007a, p. 64).

“El Mecanismo de Percepción-Acción de la empatía manifiesta concretamente que la percepción que acompaña al estado del objeto automáticamente activa el estado, situación y objeto de la representación del sujeto, y que la activación de esta representación automáticamente prima o genera respuestas automáticas y somáticas asociadas, a menos que sean inhibidas" (Preston y De Waal, 2002b, p. 4).

La idea teórica que fundamenta este modelo es la "Hipótesis de Percepción-Acción", sostenida por otros investigadores antes que Preston y De Waal, y 
que establecería, como hemos indicado, que la percepción y la acción comparten un código común de representación en el cerebro (Preston y De Waal, 2002 b, p. 9). Esta idea se habría visto confirmada tras el descubrimiento de las "neuronas espejo" por Di Pellegrino et al., (1992), y podría ser asimilada a la hipótesis del marcador somático de Damásio (2011). Las "neuronas espejo" proveen de una evidencia celular concreta de las representaciones compartidas entre la percepción y la acción, ya que se activan tanto al realizar una acción como al observar que esta acción es realizada por otro. En cuanto a la hipótesis de Damásio, trataríamos con "un caso especial de sentimientos generados a partir de emociones secundarias", que habrían quedado vinculados, a través de un proceso de aprendizaje, con los resultados futuros predecibles de determinados supuestos (Damásio, 2011, pp. 243-244). Pero las palabras "emociones secundarias" y "proceso de aprendizaje" no deberían inducirnos a error. Estas emociones secundarias necesitan a las primarias para expresarse (Damásio, 2011, p. 197), y las primarias se caracterizan por su carácter innato. Para Damásio, la mayoría de las representaciones neurales que encarnan a la sabiduría humana, tales como las normas éticas o las convenciones sociales, pueden ser vinculadas con "procesos biológicos reguladores innatos", esto es, con "impulsos e instintos", "mecanismos automáticos" que contribuyen a la supervivencia (Damásio, 2011, pp. 182-183).

\section{LOS LÍMITES DEL MECANISMO DE PERCEPCIÓN-AC- CIÓN: LA INFLUENCIA DEL DETERMINISMO GENÉTICO}

\section{a) Crítica al innatismo}

Si buceamos en la tradición filosófica, podemos encontrar en Adam Smith algunas ideas que muestran una crítica precursora del concepto de lo innato. En La teoría de los sentimientos morales, leemos: "La simpatía, en consecuencia, no emerge tanto de la observación de la pasión como de la circunstancia que la promueve." A veces, continúa Smith, "sentimos hacia otro ser humano una pasión de la que él mismo es completamente incapaz". Algo que no casa muy bien con el pretendido carácter "contagioso" de la respuesta empática, una respuesta que no deja de darse incluso en la circunstancia emocional menos transmisible de todas: "Simpatizamos incluso con los muertos" (Smith, 1997, pp. 54-55). Pero ni lo psicólogos evolucionistas, ni Preston y De Waal, ni tampoco Damásio, parecen seguidores en este punto de la teoría moral de Adam Smith, a tenor de la forma en la que han convertido al concepto de lo innato en parte de su repertorio ha- bitual. Por esta razón, conviene que nos detengamos en un importante artículo que Matteo Mameli y Patrick Bateson dedicaron a cuestionar la aportación para la ciencia que implica el uso de este concepto, un uso que no les convence en ninguna de sus aplicaciones (2006, p. 156). Por ejemplo, si definimos un rasgo innato como una determinación genética, es decir, si y solo si los genes y nada más que los genes son necesarios para su desarrollo, nos encontramos con una idea demasiado simplista porque "no hay ningún fenotipo tal que solo los genes sean necesarios para su desarrollo. Los genes por sí mismos no hacen nada. Ellos necesitan otros recursos para desarrollar la producción de fenotipo" (Mameli y Bateson, 2006, p. 158). Pero si, de una forma más matizada, intentamos definir lo innato como una influencia genética, es decir, considerando que todos los fenotipos están genéticamente influenciados porque los genes participan, de una manera u otra, en el desarrollo de todos ellos, entonces "esta propuesta es incapaz de proveer una distinción científicamente útil que se adecue aproximadamente a la distinción popular entre los rasgos innatos y no innatos" (Mameli y Bateson, 2006, p. 159). Algo parecido sucede cuando utilizamos la adaptación darwiniana como piedra de toque, porque no todas las adaptaciones darwinianas tienen un origen genético: un fenotipo puede caer dentro de la selección natural sin que se trate de una variación genética. Pero incluso en el caso de que esto sea así, es decir, que la adaptación se produzca por el efecto de una mutación genética, precisamente por ello tendríamos que reconocer que esta variación no es innata (Mameli y Bateson, 2006, p. 173). Lo importante, en cualquier caso, es que la variación genética acumulada por actitudes puede afectar a los rasgos aprendidos, de manera que estos rasgos pueden y suelen ser adaptaciones darwinianas estándar. Esto sucede cuando una mutación interviene sobre una actitud que potencia un rasgo aprendido, como sería el caso de una especie de águila pescadora cuya habilidad para pescar, producto de un largo y complicado proceso de aprendizaje, es potenciada por la aparición de una mutación genética (Mameli y Bateson, 2006, p. 174). Mameli y Bateson denuncian el uso indiscriminado que algunos investigadores realizan de la etiqueta "innato", convirtiéndola en un concepto "proteico" que les induce a confundir nociones que deberían ser distinguidas unas de otras. En concreto, apuntan a la asunción, por parte de los psicólogos evolucionistas, de que si una estructura cognitiva humana es producto de una adaptación darwiniana estándar, y por tanto, de un rasgo canalizado y desarrollado a través de su relación con el medio ambiente, se manifestará con la misma fidelidad en un 
entorno ambiental completamente distinto. La psicología evolucionista suele ubicar la aparición de lo que ellos Ilaman "pensamiento adaptativo" en el Pleistoceno, pero no hay ninguna razón para creer que los genes vayan a provocar hoy las mismas estructuras mentales que provocaban entonces. "El entorno de desarrollo de las estructuras cognitivas humanas ha cambiado de muchas importantes y evolutivamente impredecibles maneras" (Mameli y Bateson, 2006, pp. 179-181).

\section{b) Los círculos de la moral}

Si toda la cadena de la moralidad se pone en marcha con un primer impulso que se activa de forma automática e inconsciente, podemos darle la razón a Mencio en la frase que abre este artículo. De Waal lo hace por partida doble. En El mono que llevamos dentro, las palabras de Mencio son traídas a colación de los "impulsos genuinamente cooperativos" y las "inhibiciones" que constituyen el núcleo de la empatía (De Waal, 2007b, p. 196). Cuando vemos a un niño a punto de caer a un pozo, todos sentimos "sin excepción" un profundo sentimiento de angustia y alarma. Este sentimiento, continúa Mencio, no obedece a ninguna clase de motivación egoísta. Es esencialmente humano. Algo con lo que De Waal manifiesta no poder estar más de acuerdo. Volverá a repetirlo en Primates y filósofos, donde vinculará el sentimiento de angustia descrito por Mencio con el MPA:

\footnotetext{
"La idea central que subyace en las tres afirmaciones es que la angustia que sentimos al contemplar el dolor ajeno es un impulso sobre el que no ejercemos prácticamente ningún control: nos atrapa al instante, como un reflejo, sin tiempo para sopesar los pros y los contras. Las tres apuntan hacia la existencia de un proceso involuntario como mecanismo de percepción-acción (MPA)" (De Waal, 2007a, p. 79).
}

Pero al lado de las palabras de Mencio, tenemos la evidencia histórica del testimonio de Auschwitz. No solo no es cierto que todos los hombres, sin excepción, sientan un profundo sentimiento de angustia cuando ven a un niño a punto de caer a un pozo, sino que algunos ejemplares de la especie humana han demostrado ser capaces de un comportamiento tan horrible como el que supone cavar un pozo para arrojar a un niño dentro. De Waal tiene un argumento para responder a esto. Puesto que el origen evolutivo de los sentimientos que intervienen en los procesos morales tiene que ver con el reforzamiento de la cooperación y la armonía intracomunitarias, "los sistemas morales están irremediablemente predispuestos a favorecer la división intragrupal" (De Waal, 2007a, p.
204). "Llevamos en la sangre", dice De Waal, una "distinción" entre la orientación hacia nuestro propio grupo y la consideración hacia el exterior del mismo (De Waal, 2007a, p. 204). No se trata únicamente, añade De Waal, "de que tengamos prejuicios a favor de los círculos situados más al interior (nosotros mismos, nuestra familia, nuestra comunidad, nuestra especie) sino que debemos tenerlos. La lealtad es una obligación moral" (De Waal, 2007a, p. 205). Por supuesto, estos círculos pueden ampliarse, pero solo lo hacen si la salud y la supervivencia de los círculos inferiores está asegurada.

Aunque De Waal escribe esta frase en el contexto de su debate con Singer acerca de la ampliación del círculo de la moralidad hacia los animales no humanos, no parece estar ajeno a la posibilidad de que este argumento pueda aplicarse al interior de la propia especie. De hecho, el autor incluye un gráfico en su libro que muestra a las claras que la pirámide de los círculos de la moralidad tiene en su peldaño más alto al "yo", en su más bajo, a "todas las formas de vida", y en los tramos intermedios, empezando por arriba, a la "familia o el clan", la "comunidad", la "tribu o nación" y la "humanidad" (De Waal, 2007a, p. 206). De Waal no pasa por alto que el ejemplo histórico más sangrante de la aplicación de estos círculos de la moralidad es la fabricación ideológica de un grupo ajeno llevada a cabo por Adolf Hitler (De Waal, 2007b, p. 142). La configuración de estos círculos es una construcción social, pero la psicología que determina esta construcción, es "incluso anterior a nuestra especie". De Waal camina aquí por la cuerda floja. Su descripción de los círculos de la moralidad como una configuración de carácter social le permite esquivar el terreno pantanoso que conduce a la comunidad de sangre y suelo (Blut und Boden). Pero al sostener que este tipo de construcciones reflejan una predisposición natural está realizando una contribución innecesaria a los argumentos de los que tratan la mera existencia de esta predisposición como una condición suficiente para justificar cualquier teoría. Sin embargo, en un contexto diferente, De Waal advirtió de los riesgos que implica una interpretación demasiado laxa de lo que son los procesos adaptativos. Podemos verlo en la crítica que realizó a Thornhill y Palmer (2000) cuando estos argumentaron que la violación había sido favorecida por la selección natural porque impulsaba la reproducción masculina. Pero la violación se da, escribió De Waal, "en la interconexión de sexo y poder, dos áreas ricas y complejas del comportamiento humano que están claramente interrelacionadas" (De Waal, 2002, p. 188). Y además, añadió, si queremos considerarla una adaptación, deberíamos 
ser capaces de delimitar su propia base genética de la que formaría parte de otras tendencias sexuales o rasgos de la personalidad, tales como la impulsividad o la agresividad (De Waal, 2002, p. 188). Llegados a este punto, no vemos por qué no deberíamos aplicar este mismo razonamiento a los intentos de reducir la "división intragrupal" a un proceso adaptativo, asentado sobre los "prejuicios" que supuestamente "llevamos en la sangre". Las fronteras comunitarias también son instituidas en la interrelación de un entramado complejo donde intervienen las relaciones de poder y la práctica del intercambio sexual, y su base genética es tan difícil de delimitar como la que sustenta a la pretendida predisposición natural a la violación. En ambos casos, además, lo que está en el fondo es la aplicación de esa lógica de maximización genética que según los psicólogos evolucionistas determina la orientación de los individuos hacia los miembros de su mismo grupo. Pero Susan McKinnon, desde el punto de vista de la antropología, y respaldada por multitud de prácticas sociales que contradicen la existencia de esta lógica, ha señalado que los agrupamientos de parentesco y los patrones de crianza, altruismo y asignación de los recursos, se derivan de clasificaciones y comprensiones culturales que son los que realmente intervienen sobre el comportamiento. "En todas partes las categorías de parentesco siguen lógicas culturales específicas que siempre exceden y rebasan los límites de cualquier presunto cálculo universal de las relaciones genéticas" (McKinnon, 2012, pp. 61-68). Por consiguiente, si la división intragrupal puede ser explicada de forma satisfactoria a través de un sistema simbólico, mediado culturalmente, no tenemos ninguna razón para acudir a una mediación natural, una explicación mucho más insatisfactoria, y que por su contenido genérico, como dirían Mameli y Bateson, no es capaz de ofrecer una distinción científicamente útil. Su única razón de ser, en nuestra opinión, es resolver la contradicción interna que aparece en una teoría que postula el carácter innato del mecanismo psicológico que produce el contagio emocional, y los hechos que demuestran que este contagio no se manifiesta universalmente. Como hemos visto, De Waal está lejos de sostener que el ser humano sea esclavo de sus impulsos, o que estos no sean lo suficientemente variados como para permitirnos seleccionar entre ellos los más amables y benévolos. Pero el riesgo de este tipo de explicación es que las verdaderas causas de fenómenos tales como la xenofobia o el racismo queden solapadas bajo el manto de los instintos naturales, y que las supuestas determinaciones genéticas del comportamiento sean utilizadas por otros investigadores menos cautos que
De Waal para justificar situaciones de dominación o desigualdad social, como han denunciado cabalmente Lewontin, Rose y Kamin (2009), McKinnon (2012, pp. 147-156) y Mehta (2014), entre otros.

\section{c) La moral ante los imperativos de la "biología mamífera"}

En este sentido, por mencionar solo un ejemplo, podemos leer la afirmación que hace De Waal de la existencia de una diferencia de género en la empatía humana, que estaría sustentada en "una larga línea de madres que cuidaban, alimentaban, transportaban, confortaban y defendían a sus hijos" (De Waal, 2007 b, p. 18). Esto habría dado como resultado el que las mujeres tuvieran una capacidad "natural" más desarrollada que la de los hombres para apreciar la "necesidad de conexión" que produce la empatía. No discutiremos, al menos para algunas sociedades históricas, que las mujeres hayan mostrado una mayor capacidad para sentir empatía que los hombres. Lo que nos parece más cuestionable es considerar que esta capacidad haya estado determinada genéticamente, en lugar de considerarla como un producto de las relaciones sociales y culturales. De Waal nos ofrece una muestra clara de hacia dónde puede derivar esta estrategia argumentativa cuando mezcla en un solo párrafo la tendencia a favorecer a las mujeres en los casos de custodia de los hijos, con "la célebre «doble vara de medir» favorable a los hombres en el terreno de la infidelidad matrimonial" (De Waal, 2007a, p. 203). El trabajo de campo de los antropólogos ha demostrado que "la incidencia de la promiscuidad en hombres y mujeres varía transculturalmente" (McKinnon, 2012, p. 93). Se trata, por tanto, de una actitud cultural, y lo mismo podría decirse de los principios que intervienen en los procesos de custodia de los hijos. De Waal concluye este párrafo con una advertencia:

\footnotetext{
"De manera que aun cuando nos esforcemos por alcanzar un estándar moral que no tenga en cuenta las diferencias de género, los juicios que realizamos en la vida real no son inmunes a la biología mamífera. Un sistema moral viable rara vez permite que sus normas se desvinculen de los imperativos biológicos de la supervivencia y la reproducción" (De Waal, 2007a, p. 203).
}

La apelación a los imperativos de la "biología mamífera" era el resultado probable de algunas de las premisas que de De Waal termina por asumir en su intento de desentrañar las raíces evolutivas de la moralidad humana. Estas premisas están estrechamente emparentadas con la psicología evolucionista, pero en última instancia comparten un suelo común con 
la sociobiología, donde ya recibieron importantes críticas por parte de autores como Stephen Jay Gould (Allen et al., 1975), Richard Lewontin, Steven Rose y Leon J. Kamin (2009). Tomaremos la obra conjunta de estos últimos para intentar condensar en tres apartados sus argumentos. En primer lugar, el hecho de que nos encontramos ante una descripción de la naturaleza humana que consiste "en una lista extensiva de características que se consideran universales en las sociedades humanas", tales como la territorialidad, la xenofobia, la guerra o la actividad empresarial (Lewontin et al., 2009, pp. 335-336). En segundo lugar, la afirmación de que estas características universales están codificadas en el genotipo humano. $Y$ en último lugar, la pretensión de que estos "universales sociales humanos genéticamente determinados han sido establecidos por selección natural en el curso de la evolución biológica humana" (Lewontin et al., 2009, p. 336). A lo largo de su exposición, Lewontin, Rose y Kamin ofrecen multitud de razones para considerar que estos tres supuestos deberían ser desechados por la ciencia. Sería demasiado prolijo reproducir aquí el hilo completo de su argumentación, pero sí podemos señalar algunos de sus jalones más importantes.

\section{d) Crítica a la sociobiología y al determinismo genético}

En primer lugar, Lewontin, Rose y Kamin consideran que es necesario poner en cuestión el tratamiento que la sociobiología realiza de categorías tales como la dominación, la territorialidad o la agresión, como si fueran objetos naturales que poseyeran una realidad concreta, "en vez de darse cuenta de que son constructos ideológica e históricamente condicionados" (Lewontin et al., 2009, 340). En segundo término, los autores afirman que todas las tentativas que se han realizado para relacionar cualquier aspecto del comportamiento social humano con un gen particular o un conjunto de genes han fracasado (Lewontin et al., 2009, 347). Esto, que vale para los intentos, siempre fallidos, de relacionar con la herencia los resultados (en sí mismos, problemáticos), de los test de Cociente Intelectual $(\mathrm{Cl})$, y que vale también para poner en cuarentena cualquier intento de explicar los roles de género en base a supuestos instintos naturales (recordemos los imperativos de la "biología mamífera" sugeridos por De Waal), es suficiente para hacernos sospechar de la capacidad del MPA para dar cuenta del carácter innato de los impulsos que orientan la moralidad. El problema, sostienen los autores, radica en que "los rasgos manifiestos de un organismo -su fenotipo- no están en general determinados por genes aislados, sino que son una consecuencia de la interacción de los genes y el medio ambiente durante su desarrollo" (De Waal, 2009 , p. 348). Esto produce unas condiciones tales de variabilidad en los portadores e indeterminación en la naturaleza del efecto, que resulta imposible para cualquier genetista confirmar la existencia de los genes vinculados al comportamiento.

Lewontin, Rose y Kamin critican el uso y el abuso que Wilson, el padre de la sociobiología, hace de términos como "tendencias", "predisposiciones" o "propensiones", para soslayar el comportamiento condicionado por las circunstancias, poniendo en su lugar la teoría de que los genes dictan el comportamiento (Lewontin et al., 2009, p. 350). Lo mismo podría decirse en el caso de De Waal. Hay un paso ilegítimo de la observación a la explicación. No se puede tomar la universalidad aparente de un carácter como una evidencia de su determinación genética. El hecho de que la mayoría de los finlandeses sean luteranos, no significa que deba haber un gen para ello. Esto, que parece evidente para los finlandeses, debería valer también para la relación entre el comportamiento social humano y el de los primates. La supuesta homología entre el comportamiento de unos y otros es una versión distinta del mismo argumento que confunde la observación con la explicación. La homología considera que comportamientos similares entre especies distintas son derivados de un antepasado común. La analogía, por el contrario, considera que han sido derivadas de forma independiente. De Waal mantiene que, dado que los simios y los humanos son "especies íntimamente relacionadas", es "enteramente imposible" que sus similitudes de comportamiento se deban a la analogía (De Waal, 2007a, p. 210). Pero Lewontin, Rose y Kamin recuerdan que "los humanos no tienen parientes vivos muy próximos" (2009, p. 352). No existe ninguna otra especie que esté clasificada en el mismo orden genérico (Homo), el antepasado común más reciente debe remontarse por lo menos a hace dos millones de años, y además, la conducta que podría ser genéticamente estereotipada en lo simios, podría haber sido aprendida tempranamente en los humanos (Lewontin et al., 2009, pp. 352-353). Los autores consideran oportuno volver a insistir en que no se ha realizado ningún estudio que demuestre la heredabilidad de las características de la personalidad humana, que no cabe confundir con la familiaridad (Lewontin et al., 2009, p. 353).

Por último, en cuanto a la pretensión de la sociobiología de que estos supuestos universales humanos genéticamente determinados hayan sido establecidos por selección natural, Lewontin, Rose y Kamin critican 
la práctica habitual entre los seguidores de esta teoría de tomar a las características que son objeto de su estudio como las causas eficientes de su propia evolución. Sin embargo, "hay un importante componente de ruido aleatorio en el desarrollo y la fisiología" (Lewontin et al., 2009, p. 364). Estos procesos, que se despliegan a nivel molecular y celular, intervienen también, junto al genotipo y el medio ambiente, en la producción del fenotipo. Pero la sociobiología no tiene nunca en cuenta esta y otras fuerzas evolutivas que son claramente no adaptativas y que podrían constituir explicaciones adecuadas para numerosos sucesos evolutivos concretos (Lewontin et al., 2009, pp. 362364). Lewontin aborda con detalle este tipo de fuerzas en un trabajo anterior. Un ejemplo de ellas son las modificaciones al azar de las frecuencias genéticas que provoca el tamaño limitado de las poblaciones. En resumen, no siempre hace falta una explicación adaptativa. Es inútil investigar por qué para los rinocerontes es más favorable tener dos cuernos en África y un solo cuerno en la India (Lewontin, 1981).

\section{LA FÁBRICA DE LA EMPATÍA: UNA INTERPRETACIÓN SOCIAL DE LA HIPÓTESIS DE PERCEPCIÓN-ACCIÓN}

Desde nuestro punto de vista, el Mecanismo de Percepción-Acción desarrollado por Preston y De Waal fracasa en su pretensión de dar cuenta del carácter innato de los impulsos e inhibiciones que se encuentran en el núcleo de la empatía. Sin embargo, la hipótesis de la percepción-acción sí podría sustentar la conexión entre la esfera de la actividad psicológica y la esfera de la actividad neural. La relación entre ambos procesos no tiene por qué depender de un núcleo de programación genética, sino que, al contrario, los impulsos e inhibiciones que De Waal inscribe en esta programación podrían ser el resultado, y no la causa, de la actividad neural y psicológica. El hecho de que determinadas respuestas emocionales se activen de forma inconsciente y automática no implica que estas respuestas estén necesariamente codificadas en nuestro ADN. La búsqueda de fenómenos universales en el comportamiento humano conduce habitualmente al fracaso. No lo es el tabú del incesto, cuya incidencia, curiosamente, tampoco se reduce en las sociedades occidentales que tanto se han preocupado por legislar en su contra (Lewontin et al., 2009, p. 187). Y no lo es, como hemos intentado explicar, la empatía. En nuestra opinión, para comprender este fenómeno resulta mucho más apropiado concentrar nuestra atención en las influencias sociales y culturales que se despliegan alrededor suyo.
A menudo, los defensores del determinismo genético han recurrido al trabajo con niños para intentar localizar un comportamiento puro, no contaminado culturalmente, sobre el que poder aplicar la reducción genética. Preston y De Waal también intentaron algo parecido para fundamentar el MPA (De Waal, 2002b, pp. 7-9). Pero Lewontin, Rose y Kamin, ya dieron argumentos convincentes contra esta posibilidad. Los niños solo pueden desarrollarse en un entorno que incluya el factor social desde la fecha de su nacimiento (Lewontin et al., 2009, p. 195). Son estas relaciones sociales las que intervienen en la producción de las emociones. La hipótesis de la percepción-acción da cuenta del proceso por el cual estas relaciones se inscriben en la actividad psicológica formando el núcleo afectivo de la empatía. Pero las relaciones sociales, en el ser humano, están siempre mediadas a través del lenguaje, de manera que el lenguaje desempeña un papel crucial en la construcción de las emociones. Hauser (2008), a partir de ciertas ideas de Mikhail (Gross, 2011, 21 de diciembre), ha intentado enlazar teóricamente la gramática lingüística universal postulada por Chomsky con una gramática moral universal. Pero esta relación vuelve a conducirnos al escabroso dominio de los principios innatos. Y además, supone la conclusión de que todos los animales que no participan de esta gramática lingüística son incapaces de experimentar emociones morales, como la culpa, la vergüenza o la empatía (Hauser, 2002, p. 338). Sin embargo, nosotros pensamos que aquí los esfuerzos que ha realizado De Waal para demostrar lo contrario son más convincentes que la postura de Hauser. Lo que hoy conocemos del comportamiento de los simios y otras especies animales hace que resulte cada vez más difícil sostener que el ser humano sea la única especie que tenga emociones y sea capaz de experimentar empatía. Pero una vez abandonemos la premisa de los principios innatos podemos considerar que el proceso de construcción de las emociones del que da cuenta la hipótesis de la percepción-acción no se realiza solamente a través de los actos de habla. EI ser humano, al igual que los simios, utiliza para comunicarse un sistema amplio de signos corporales, incluyendo señales de índole visual, sonora y olfativa. Por consiguiente, la tesis que postulamos, según la cual las emociones se inscriben a través del lenguaje, debe considerarse en un sentido amplio que incluya los signos corporales y otros sistemas de comunicación que compartimos con los simios y otras especies.

La fabricación de las emociones, en el caso del ser humano, lleva la impronta particular de los actos del habla. Esto les otorga un carácter singular, diferente 
al que pueda experimentar cualquier otra especie. Pero esto no significa que otras especies, o los seres humanos antes de adquirir competencias lingüísticas, no puedan producir emociones parecidas. Es evidente que determinadas emociones, como la acidia medieval, están demasiado vinculadas al contexto histórico o a la intervención del habla como para que un simio o un delfín puedan experimentarlas (en realidad, nadie siente ya acidia, tal y como la pudieron sentir nuestros antepasados [Belli, 2009, p. 33]). Pero también sucede lo mismo en sentido inverso. Es difícil que un ser humano pueda experimentar el tipo de emociones que siente un delfín o un bonobo, cuando estas emociones están vinculadas a determinados comportamientos que son singulares de estas especies. Sin embargo, si estas emociones han sido construidas mediante un tipo de interacción social que reproduce unas condiciones similares de interacción entre los individuos de otra especie, pensamos que es legítimo establecer un paralelismo entre ambas situaciones afectivas. La clave aquí será precisar con rigor en cada caso cuáles son las condiciones que nos permiten establecer la comparación. Pensamos que De Waal ha descrito muchas de estas situaciones en su trabajo de campo con bonobos y chimpancés. La diferencia con nuestro planteamiento es que lo que él considera comportamientos homólogos, es decir, derivados de un antepasado común, nosotros los consideraríamos análogos, productos de una evolución independiente. Pero estos términos no terminan de ser apropiados, puesto que en última instancia remiten a la evolución, y no es en el campo de la evolución donde nosotros pensamos que deban establecerse los términos de la comparación. En el caso de especies que presenten un alto grado de desarrollo social y cognitivo es necesario prestar atención a la manera en la que las relaciones sociales podrían estar interviniendo en la determinación del comportamiento, así como también en la producción social de las emociones. De Waal ha descrito cómo la igualdad de géneros entre los chimpancés es mucho más acusada en los zoológicos que en libertad. La razón es que en situación de libertad las hembras tienen que deambular solas con sus críos dependientes, buscando por separado las frutas y hojas con que se alimentan, y esto no les permite formar alianzas con otras hembras como las que se producen en la situación de confinamiento, donde los gritos de una hembra atacada por un macho pueden suscitar la ayuda de las demás. Una coalición de hembras de chimpancé es un asunto serio para un macho abusón, que no tardará en salir corriendo si no quiere recibir una brutal paliza (De Waal, 2007b, p. 71). Lo que de- termina el empoderamiento femenino de las hembras de chimpancé, frente a la situación que viven en libertad, no es un cambio en su biología, sino en las relaciones sociales que hacen posible la formación de coaliciones. De la misma manera, podemos aventurar que el tipo de emociones que sienten las hembras de chimpancé que forman parte de una coalición, no debe ser el mismo que el que experimentan las que viven sometidas a un grado mayor de violencia masculina. Las semejanzas que estas emociones, y este comportamiento, puedan tener con otros parecidos que se den entre especies distintas, tienen más que ver con el paralelismo social que con la homología o analogía evolutiva.

La interpretación que estamos abordando aquí de la hipótesis de la percepción-acción puede conectarse con el concepto de performatividad de Judith Butler. Si sustituimos la determinación biológica por una construcción cultural corremos el riesgo de reproducir, invirtiendo los términos de la determinación, el dualismo ontológico. Los cuerpos no pueden ser pensados como una mera superficie de inscripción de la cultura desde el momento en que su materialización aparece indisociablemente unida a los efectos de la significación cultural (Butler, 2002, p. 19). El dualismo que De Waal trata de conjurar, vuelve a hacer acto de presencia cuando trata a los instintos y emociones que se encuentran en el núcleo de la empatía como si fueran predisposiciones innatas. Pero nuestra programación genética no tiene nada que ver con la aparición de instintos y emociones concretas, sino con la capacidad de tenerlos, tal y como el hecho de nacer con la capacidad de experimentar acidia, una emoción medieval, no implica en absoluto que una persona moderna vaya a tenerla en su vida. Los instintos, desde el principio, son producidos y reproducidos a través de un proceso o actividad constante que conforma la materialidad del cuerpo, un proceso caracterizado por la reiteración de normas, como el que determina la construcción del género (Butler, 2002, p. 29). Además:

\footnotetext{
"Dichos actos, gestos y realizaciones -por lo general interpretados- son performativos en el sentido de que la esencia o la identidad que pretenden afirmar son invenciones fabricadas y preservadas mediante signos corpóreos y otros medios discursivos" (Butler, 2007, p. 266).
}

Lo interesante de este concepto de performatividad, como señala Simone Belli, es que considera a la emoción como una performance producida a través de fabricaciones. Dado que "las emociones no existen antes de sus performances", no son el producto de una predisposición innata, sino la expresión de unos 
actos o fabricaciones que pueden devenir normativos y ser vistos como naturales, a través de su ejecución repetida en el tiempo, "en un conjunto de múltiples interacciones sociales cotidianas" (Belli, 2009, p. 27). A la luz de esta interpretación, quizás la evidencia que nos ofrecen las neuronas espejo no sea solo la de la existencia de un código común de representación entre la percepción y la acción, sino la de una actividad performativa, el reflejo a nivel celular del proceso de fabricación de las emociones.

La solidaridad, el altruismo, la cooperación, no están determinados genéticamente. La moralidad es una disposición práctica, y los impulsos que la determinan están producidos y reproducidos, a través de una actividad siempre abierta, por la fábrica de las emociones. Intentar explicar la empatía por la evolución natural es como intentar explicar los frescos de la Capilla Sixtina por la evolución natural de la mano de Miguel Ángel. La empatía no puede aparecer si no se han dado antes una serie de condiciones materiales que son producto de la evolución natural, pero estas condiciones no prefiguran la empatía más de lo que el desarrollo del pulgar oponible prefiguró los frescos de la Capilla Sixtina. Somos animales sociales. Los simios también. Pode-

\section{NOTAS}

1 La traducción española dice "mono". "Simio", sin embargo, se corresponde mejor con "ape".

\section{BIBLIOGRAFÍA}

Allen, E. Beckwith, B., Beckwith, J., Chorover, S., Culver, D., Duncan, M. y Gould, S. J. (1975). Against "Sociobiology». New York Review of Books, 22, 19, pp. 43-44.

Ardrey, R. (1961). African Genesis. A personal Investigation into the Animal Origens and Nature of Man. New York: Atheneum.

Ardrey, R. (1966). The territorial Imperative: A Personal Inquiry into the Animal Origins of Property and Nations. New York: Atheneum.

Ashley Montagu, M. F. y otros (1970). Hombre y agresión. Barcelona: Kairós.

Belli, S. (2009). La construcción de una emoción y su relación con el lenguaje: revisión y discusión de un área importante de las ciencias sociales. Theoria, 18, 2, pp. 15-42.

Benton, T. (2000). Social Causes and Natural Relations. En Rose, H. y Rose, S. (comps.). Alas, Poor Darwin: Arguments against Evolutionary Psychology. Nueva York: Harmony Books, pp. 249-272. mos considerarlos sujetos de derechos, como quiere Singer (2007 y 2011), o beneficiarios de obligaciones humanas, como prefiere De Waal. Pero ninguna de ambas declaraciones hará brotar el sentimiento de la empatía del oscuro espíritu del cazador. Muchas personas sienten empatía ante el sufrimiento animal. Pero esta empatía no es producto de una predisposición innata, sino de una manera determinada de relacionarse con los animales. Un granjero puede sentirse gravemente conmocionado ante la muerte del perro de la familia, pero no sentir ningún sufrimiento ante el hacinamiento de los animales que constituye su forma de ganarse la vida. En última instancia, puede incluso mostrar la misma falta de empatía hacia otras personas. Y no hace falta que vivan en otro continente. Pueden ser vecinas suyas, o incluso miembros de su propia familia. La empatía es una emoción maravillosa que parece brotar espontáneamente... cuando lo hace. Pero no es un misterio que podamos desentrañar acudiendo a la genética como si fuera el árbol del bien y del mal. La respuesta no está en lo genes, sino en la manera en la que el desprecio o el amor al prójimo se manifiestan tan arraigados en el corazón de algunas personas que parecen estar escritos en su ADN.
2 La de Mencio y otras dos de Westermarck (¿Podemos evitar sentir compasión por nuestros amigos?) y Smith (Por muy egoísta que supongamos al hombre...). Cf. De Waal (2007a, p. 26 у р. 40).

Butler, J. (2002). Cuerpos que importan. Sobre los límites materiales y discursivos del "sexo". Buenos Aires: Paidós.

Butler, J. (2007). El género en disputa. El feminismo y la subversión de la identidad. Barcelona: Paidós.

Damásio, A. (2011). El error de Descartes: la emoción, la razón y el cerebro humano. Barcelona: Destino.

Dawkins, R. (1993). El gen egoísta. Las bases biológicas de nuestra conducta. Barcelona: Salvat.

Dawkins, R. (1982). The extended phenotype. The long reach of the gene. Oxford: Oxford University Press.

De Waal, F. (2002). Evolutionary Psychology: The Wheat and the Chaff. Current Directions in Psychological Science, 11, 6, pp. 187191. http://dx.doi.org/10.1111/14678721.00197

De Waal, F. (2007a). Primates y filósofos. La evolución de la moral del simio al hombre. Barcelona: Paidós. 
De Waal, F. (2007b). El mono que llevamos dentro. Barcelona: Tusquets.

Di Pellegrino, G., Fadiga, L., Fogasi, L., Gallese, V. y Rizzolatti, G. (1992). Understanding motor events: A neurophysiological study. Experimental Brain Research, 91, 1, pp. 176-180. http:// dx.doi.org/10.1007/BF00230027

Gross, Ch. (2011, 21 de diciembre). Disgrace: On Marc Hauser. A case of scientific misconduct at Harvard. The Nation. Disponible en: https://www.thenation.com/article/disgrace-marc-hauser/

Hauser, M. D. (2002). Mentes salvajes. ¿Qué piensan los animales? Barcelona: Granica.

Hauser, M. D. (2008). La mente moral. Cómo la naturaleza ha desarrollado nuestro sentido del bien y del mal. Barcelona: Paidós.

Lewontin, R. C. (1981). L'evolution. La pensé, 233, pp. 16-24.

Lewontin, R. C., Rose, S. y Kamin, L. J. (2009). No está en los genes. Racismo, genética e ideología. Barcelona: Crítica.

Mameli, M. y Bateson, P. (2006). Innateness and the sciences. Biology and Philosophy, 21, pp. 155-188. http://dx.doi. org/10.1007/s1053900551440

McKinnon, S. (2012). Genética neoliberal. Mitos y moralejas de la psicología discursiva. México: Fondo de Cultura Económica.
Mehta, P. (2014). There's a Gene for That. Jacobin Magazine, 13. Disponible en: https://www.jacobinmag.com/2014/01/theresa-gene-for-that/

Pinker, S. (2000). Cómo funciona la mente. Madrid: Destino.

Posner, G. L. y J. Ware, J. (2005). Mengele. El médico de los experimentos de Hitler. Madrid: La esfera de los libros.

Preston, S. D. y De Waal, F. (2002a). The communication of emotions and the possibility of empathy in animals. En S. G. Post, L. G. Underwood, J. P. Schloss y W. B. Hurlbut (comps.). Altruism and Altruistic Love: Science, Philosophy and Religion in Dialogue. Oxford: Oxford University Press, pp. 284-308.

Preston, S. D. y De Waal, F. (2002b). Empathy: Its ultimate and proximate bases. Behavioral and Brain Sciences, 25, pp. 1-72.

Singer, P. (2007). Moralidad, razón y derechos de los animales. En De Waal, Primates y filósofos. Barcelona: Paidós, pp. 177-197.

Singer, P. (2011). Liberación animal. El clásico definitivo del movimiento animalista. Madrid: Taurus.

Smith, A. (1997). La teoría de los sentimientos morales. Madrid: Alianza Editorial.

Thornhill, R. y Palmer, C. T. (2000). A natural history of rape: Biological bases of sexual coercion. Cambridge, MA: MIT Press. 